\title{
Coffee Powder Reused as a Composite Material
}

\author{
V.Canavarro $^{1}$, B. Rangel ${ }^{1}$, J.L. Alves ${ }^{2}$ \\ ${ }^{1}$ Faculty of Engineering, University of Porto, Portugal \\ ${ }^{2}$ INEGI, Faculty of Engineering, University of Porto, Portugal
}

\begin{abstract}
With the technological and industrial development, many products have toxicity problems and the rate of using new raw materials is unsustainable. The markets have been undergoing changes and manufacturing materials tend to be affordable, but they still have problems related with pollution and ecological concerns. It is even known the impact that the hunger for consumption, that mankind shows, has in nature and that conducts to a slow end of natural resources. For this reason, alternatives pass through the reuse of waste.
\end{abstract}

This theme has emerged as a way to combat this problem of great environmental impact through design. This research aims to present a production method for reuse ground coffee leftovers. Because at the moment it is treated mostly as junk, obtaining it does not entail any costs, and may therefore be an innovative material for the production of various objects. From the point of view of sustainability the idea is to extend the life cycle of coffee, eliminating the waste phase after consumption, to which is nowadays assumed as the normal procedure.

This work has been carried out within the structure of the Master's Degree in Product and Industrial Design (MDIP), at the Faculties of Engineering (FEUP) and of Fine Arts (FBAUP) from the University of Porto. The main goal to be achieved with this research is to obtain a mouldable material, formed by the coffee grounds and a suitable binder found through testing and research. It is also intended that the material created is 
durable and washable, with prospects of extending the realities in which it can be used. The second objective will be the development of a tool for the production of this material, not only by moulding, but eventually by $3 \mathrm{D}$ printing. To validate these goals it is intended the development of a set of products with the studied technologies.

In this article are presented the results of laboratory experiences as well as some design solutions that were achieved.

\section{Keywords}

Coffee grounds, waste, reuse, design, additive manufacturing.

\section{Introduction}

This article aims to present the different strategies that are currently being adopted in the coffee reuse industries. The relevance of this study is justified by the coffee sui generis characteristics, such as odor, visual appearance or texture, as well as the huge abundance of raw materials in capability that is normally discarded after serving their primary function. The results presented here in terms of tests will translate the different mixtures used in order to obtain the intended material.

\subsection{World's Waste}

In order to realize the enormity of the problem with waste materials, biological or artificial, here is presented some data. According to Eurostat (Statistical Office of the European Union), Portugal generated in 2012, 14.184.456 tons of waste (Eurostat 2015). Europe (28 Countries) ended the same year with 2.51422 billion tons and in the United States are daily generated 624.700 tons of solid waste and the forecast made in the document "What a Waste" (Bhada-Tata 2012, 83) it is that by 2025 will be 701,709 
tons. As further demonstrated by Daniel Hoornweg, Perinaz Bhada-Tata and Chris Kennedy in their publication in the journal "Nature" (Figure 1), the amount of waste generated globally is set to increase by 2100 , with the countries of sub-Saharan Africa at the forefront (Daniel Hoornweg 2013, 616). It can thus be inferred that the generation of waste from the human being, hardly diminish in the near future and a solution to its decline can be the reuse or recycling.

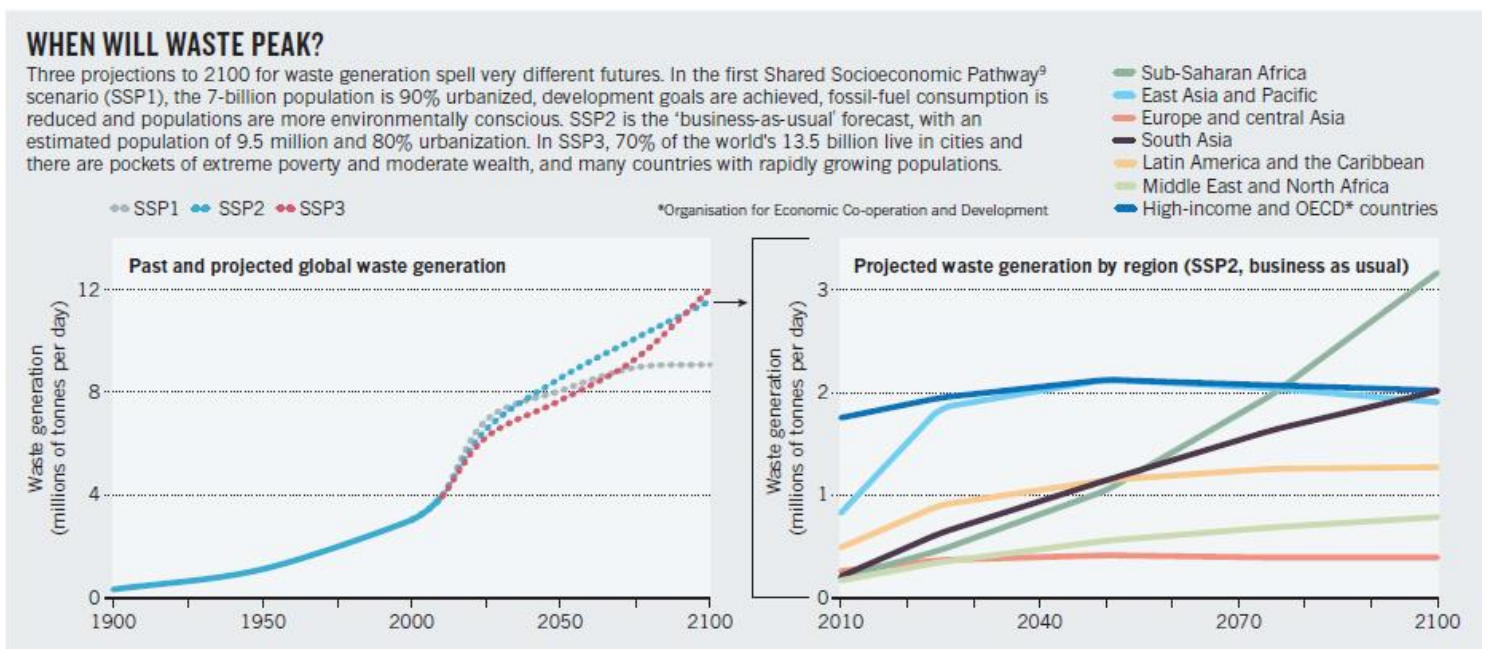

Figure 1 - Chart of the globally generated waste with projections up to 2100 .

\subsection{Coffee Data and Statistics}

Given that coffee also turns out to be a waste at the end of its life cycle and to contextualize this study, it is necessary to know some numbers. Based on data provided by the International Coffee Organization, it is estimated that its overall consumption in 2014 was of 149.8 million bags of $60 \mathrm{~kg}$ (Organization 2015th). In Portugal, in the same year, were consumed 823.000 bags and the per capita consumption was around $4.7 \mathrm{~kg}$ (Organization 2015b). According to the same source, the annual coffee consumption from 2011 to 2014 increased by $2.4 \%$ (Figure 2). It is further noted that this increase is 
gradual, having existed every year. It is therefore plausible that it will continue to occur in the near future.

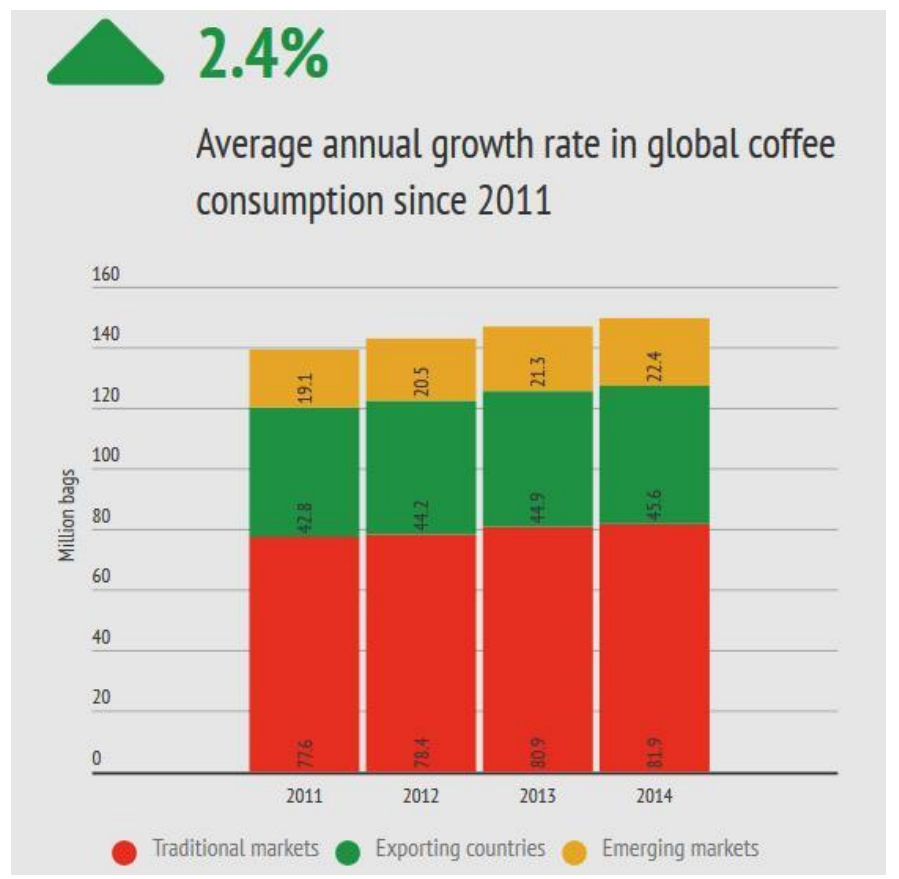

Figure 2 - Organization, International Coffee. 2015 "The Current State of the Global Coffee Trade".

\section{Coffee Reuse Strategies}

There are already reuse strategies in several areas, from agriculture to fuel. "The coffee grounds material has been consolidating itself as one of the most abundant biological resources of the world for use as green energy" (Gómez de la Cruz et al., 2015, 1). However, in the Design area there are also ways of creating products with coffee grounds based materials beginning to be explored. The solutions that have been tested in this area are divided by the features presented by the final material, as a result of different mixtures between coffee grounds and other binding materials.

An example is Kaffeeform (Figure 3). "Kaffeeform is a recycled innovative material created with coffee grounds, vegetable fibers, cellulose and biopolymers. After five 
years of experimentation and research, an original formula was created to transform old coffee in new products." (Kaffeeform 2015).

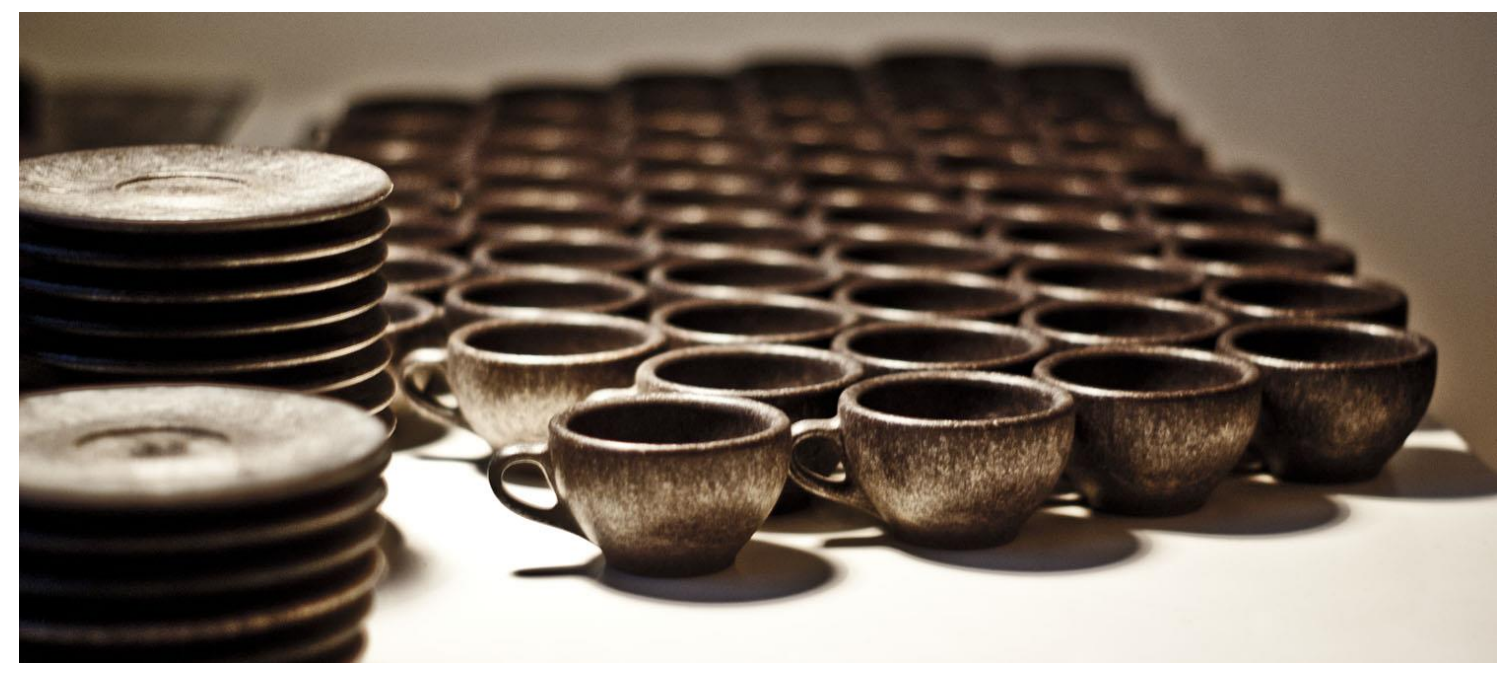

Figure 3 - Kaffeeform.

AgriDust is a design created by the Italian Product Designer Marina Ceccolini, which consists of using some food residue such as coffee grounds, peanut or orange peels mixed with a binder of potato starch base (Figure 4). "AgriDust can be used to create packaging, plant pots and, in addition, using cold technology lends itself as a material for 3D printers, in which the classical extruder is replaced by a syringe" (Ceccolini 2015).

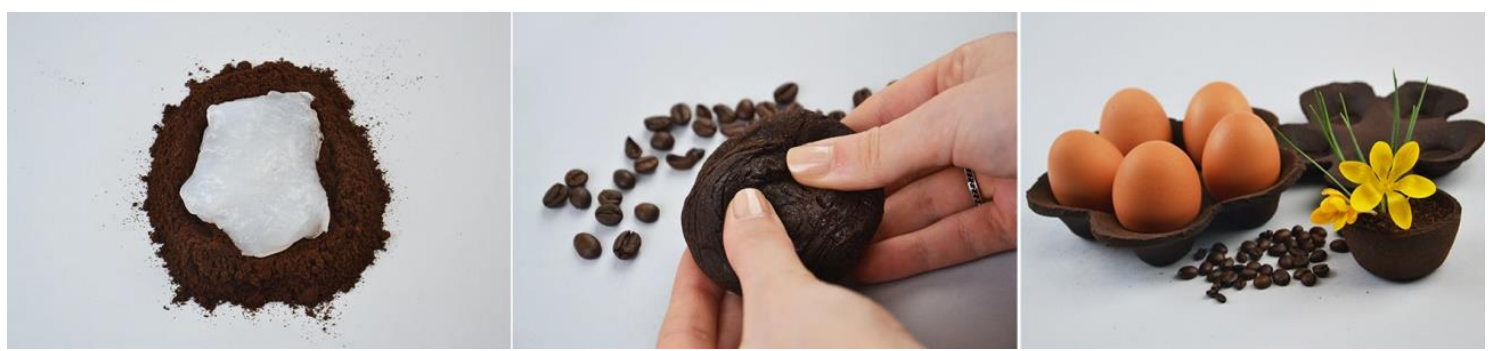

Figure 4 - AgriDust by Marina Ceccolini (Ceccolini, Marina. 2015). 
Another example of coffee use in creating raw material with $3 \mathrm{D}$ printing capabilities is the Hoop by Francesco Pacelli (Figure 5). "Francesco Pacelli, a member of + Lab at the Polytechnic University of Milan, frightened by the exponential amounts of food waste from the present to 2050 , had an interest in ways to recycle waste in a sustainable manner, combining it with an ancient material, clay "(Grellier 2015). The Hoop design by Francesco Pacelli has many similarities to the AgriDust by Marina Ceccolini, although the mixture added to coffee is completely different. In this particular case the mixture reached seeks a higher consistency. This material is also moulded and has the ability to be extruded with the aid of a syringe.

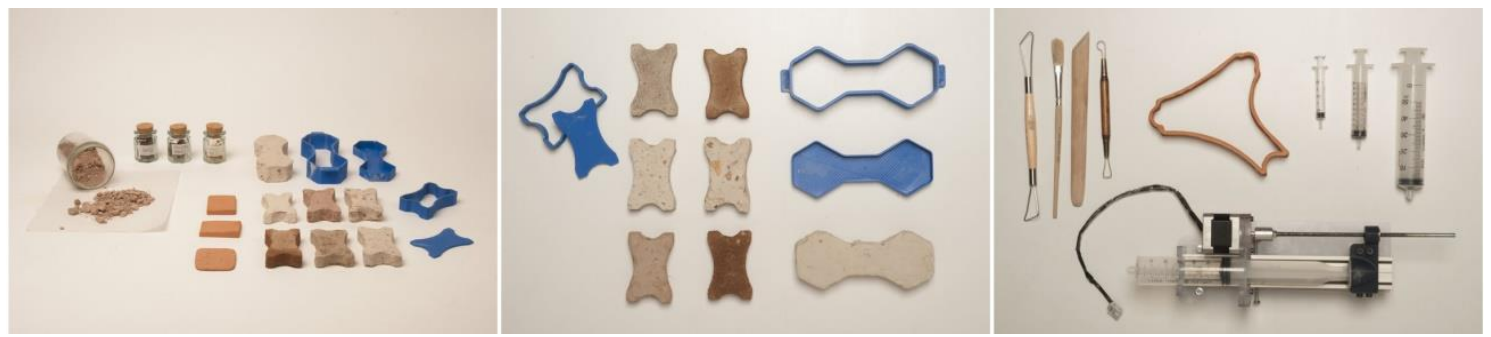

Figure 5 - Hoop by Francesco Pacelli (Pacelli, Francesco. 2015).

"Wound Up $\mathrm{P}^{\mathrm{TM}}$ is a 3D printing filament created using coffee waste by-products" (USA 2015). This material produced by the American company 3Dom uses coffee residues mixed with PLA (polylactic acid) to create a 3D printing material with visibly unique printing finishes. The filament produces a brownish colour and a natural noticeable grain (Figure 6). This is the first of a line of 3Dom USA intriguing materials called composite c2renew. More bio-based products will be launched in the near future. One of the strongest features of this product is the ability to be printed on any machine capable of printing with PLA. 

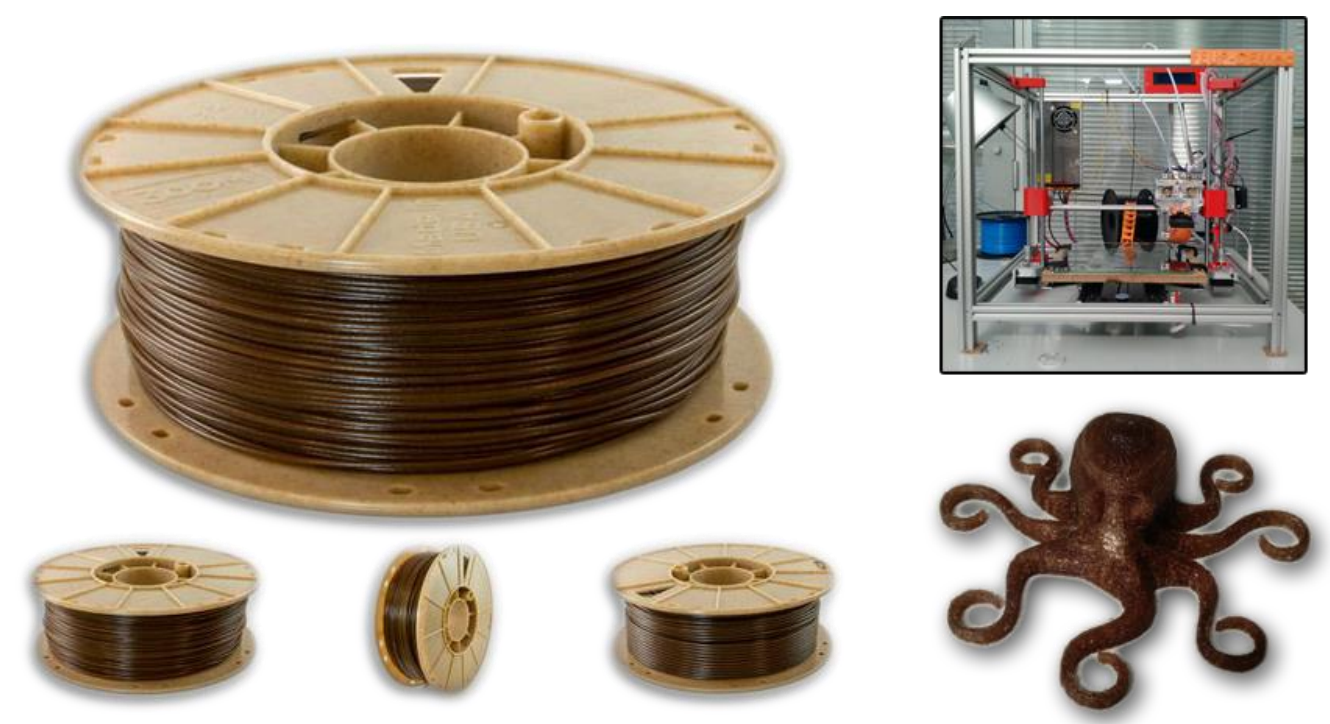

Figure 6 - Wound-up by 3Dom (USA, 3Dom. 2015).

\section{Experimental Work}

\subsection{Materials and Methods}

The experimental work appears as a way to establish the main and most suitable material to add to coffee, in creating this material.

The first binder to be tested was Biresin 83, an epoxy resin with $30 \%$ catalyst and the ratios between this material and the coffee have varied, in an attempt to understand what types of results could be obtained.

Then starch (potato and corn) was tested, because it is a natural and biodegradable polymer. Several percentages of this material were tested and the cures were made at different temperatures and for various lengths of time.

Later, tests were performed with pine resin, as it is a Portuguese material, and was available in abundance. Also in this case, the ratios varied and the cure was virtually instantaneous. 
Because pine resin showed very weak results, it was decided to add other materials to the mix in an attempt to give greater strength to the final material. Therefore wax was selected, but the results were still unsatisfactory.

Finally, tests were done using Polylactide, PLA as a binder and positive results began to appear. PLA, is a biodegradable thermoplastic derived from natural lactic acid from corn, maize or milk. Is a thermoplastic derived primarily from annually renewable resources (maize, corn or milk), and it is available in a number of grades, designed for ease of processing. In-line drying may be needed to reduce water content for extrusion and moulding. The recommended moulding temperature is $165-170 \mathrm{C}$.

It resembles clear polystyrene, provides good aesthetics (gloss and clarity), but it is stiff and brittle and needs modification using plasticizers for most practical applications. It can be processed like most thermoplastics into fibres, films, thermoformed or injection moulded (Figure 7).

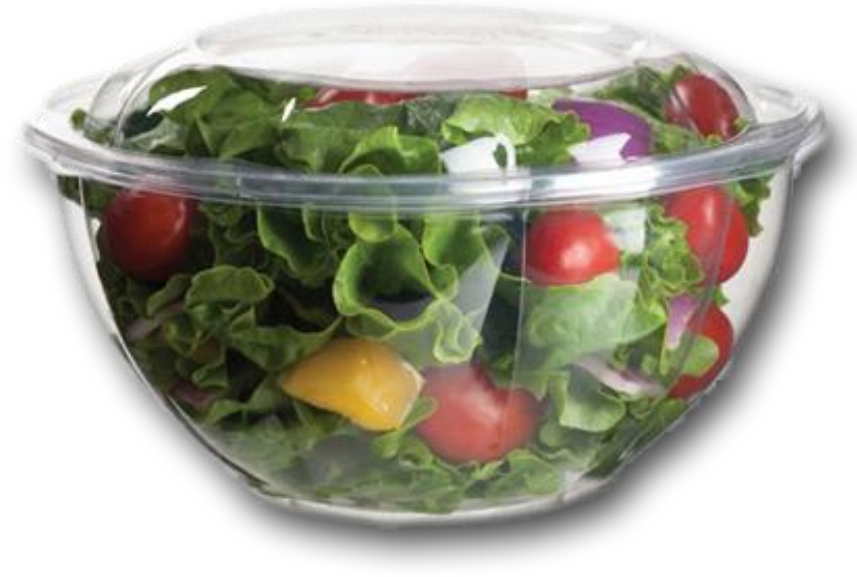

Figure 7 - Food packaging (http://makingsociety.com/2013/08/materialmatters-series-n1-pla-plastic). 
PLA is transparent and has FDA approval for food packaging. PLA film and sheet can be printed and laminated. Biopolymers are, however, expensive, costing 2 to 6 times as much as commodity plastics like polypropylene.

Food packaging, plastic bags, plant pots, diapers, bottles, cold drink cups, sheet and film are some examples of the typical applications of this material (CES EDUPACK 2016, Granta Design, UK).

This information legitimates the use of this material in the project, having into account its features with regard to food contact.

\subsection{Results and Discussion}

In the first attempt for combinations between coffee and a binding material, the choice was an epoxy resin. Figure 8 presents the results obtained with this mixture, using different ratios coffee/resin.

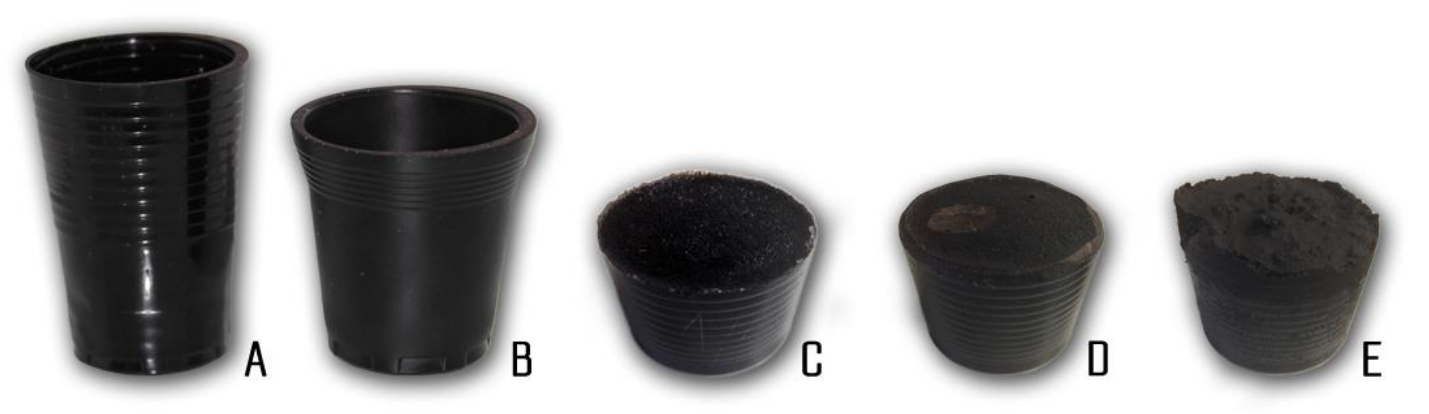

Figure 8 - Coffee cups produced with epoxy resin mixtures.

The epoxy resin used was Biresin 83 with $30 \%$ catalyst and the curing time was, as usual, 24 hours at room temperature. As a mould simple plastic coffee cups available at any coffee vending machine were used. 
Figures A and B represent tests performed to symbolise the existing coffee cups on the market. In Figure $\mathrm{C}$ the ratio used was a coffee part to four parts resin, while in Figure D the ratio was $1: 2$ and figure $\mathrm{E} 1: 1$.

These tests were performed to demonstrate the possibility of mixture between coffee remains and a binder, but have never been seen as a possibility in this project, because the used resin is not safe for food contact.

The next step was the use of starch. Being a natural, biodegradable substance, both potato and corn starches were taken into consideration for this study as potential solution.

The way to materialize this experiment involves mixing the starch with cold water to dissolve it. Then there is the mixture with a certain percentage of coffee and the product obtained was placed in an oven, using different temperatures and time to reach the best properties (Figure 9).
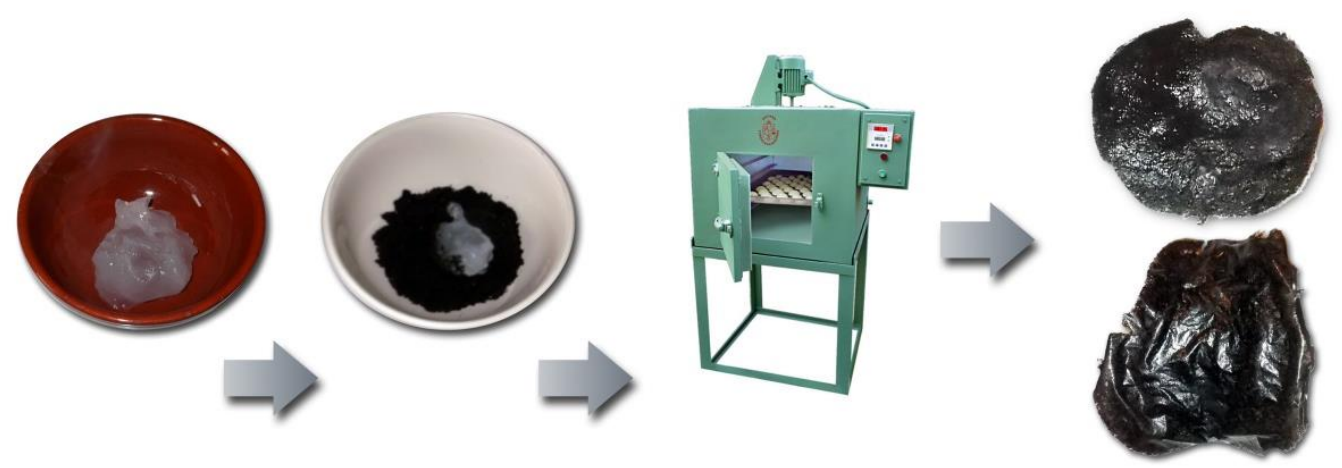

Figure 9 - Mixtures with starch.

However, this test has proven to be unsuccessful, since all the results have shown, after some time, moisture signals through mould appearance, as can be seen in Figure 10. 

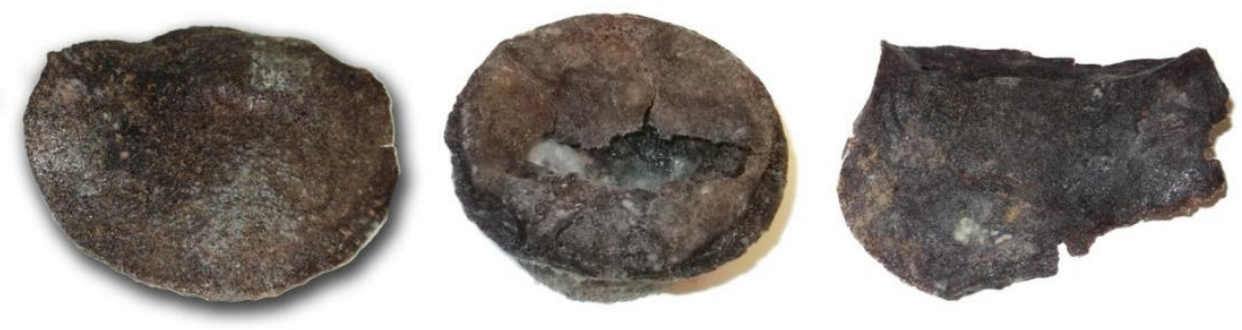

Figure 10 - Degradation of the mixtures with starch.

At a later stage it was decided to test pine resin as a binder to ascertain whether its characteristics could give a reasonable material when mixed with coffee. It was quickly realized that this union would be fruitless, given the fragility of the resin itself. It can still be seen in Figure 11 that most results have become brittle and not very rigid.

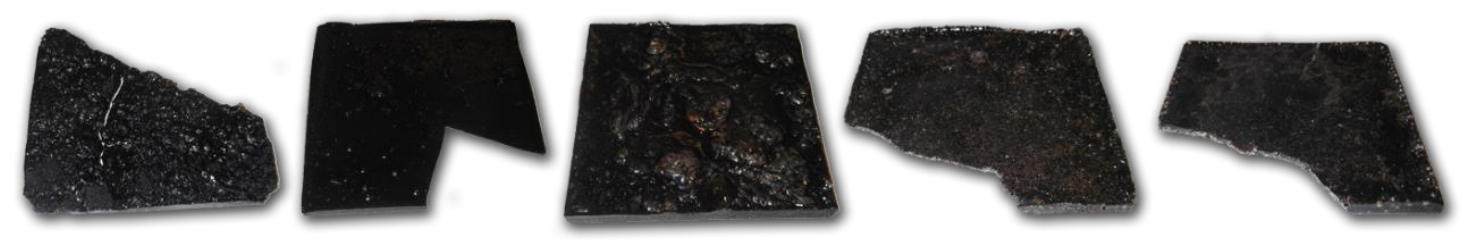

Figure 11 - Fragility of the samples of the coffee-pine resin mixtures.

After a few tests with negative results, the option was to use the same pine resin, but with wax addition in an attempt to improve its physical characteristics. As shown in Figure 12, very interesting visual results were produced, but the problem of resistance remained and the resulting material was still very brittle, thus this possibility was discarded. 


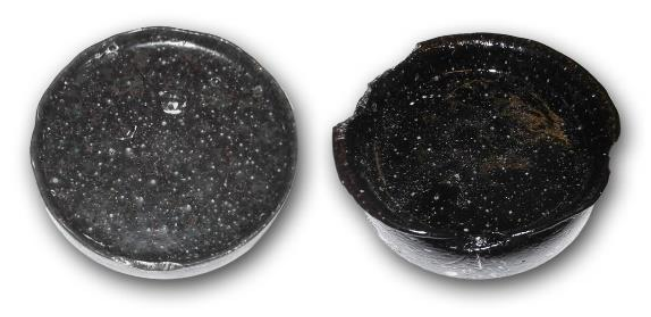

Figure 12 - Fragility of the samples of the coffee-pine resin and wax mixtures.

Finally, and after several experiments, the material chosen for the mixture with coffee, was PLA. There are several reasons for choosing this material, although the main reason is the perfect symbiosis with the coffee in the design of a perfectly mouldable and inert material in contact with food.

The figure below represents some of the first tests with PLA in conjunction with coffee residue (Figure 13). The percentages were not taken into account, but it was quickly realized it would work for the fulfilment of the pre-defined goal.
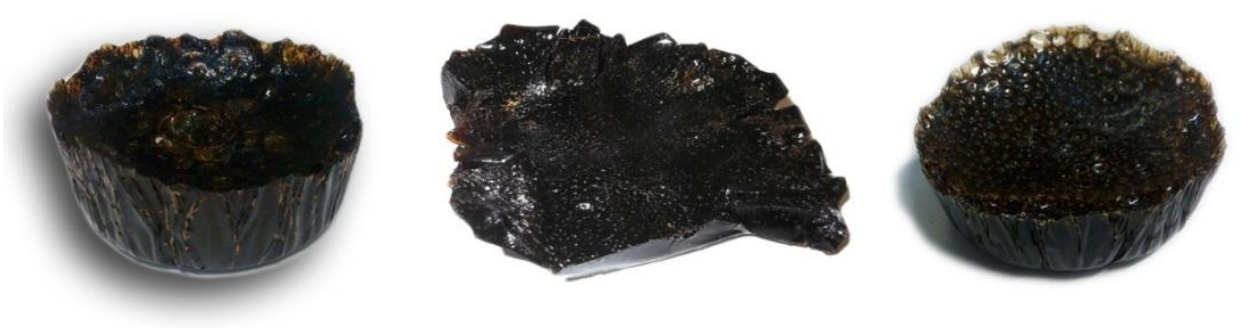

Figure 13 - Samples of coffee-PLA mixtures.

After realizing that this would be the ideal material, an exemplificative 3D model was made in Solidworks and the file was subsequently saved in STL format. From there, a 3D printed piece was created and from that a mould was made out of silicon. For the creation of this mould, the silicone used was 950 VTX, provided by SLM and the catalyst proportion was $10 \%$. The curing time was 24 hours as usual with this type of 
resin. With the mould ready, various experiments took place with different percentages of both materials to understand what would be the most suitable mixture (Figure 14).
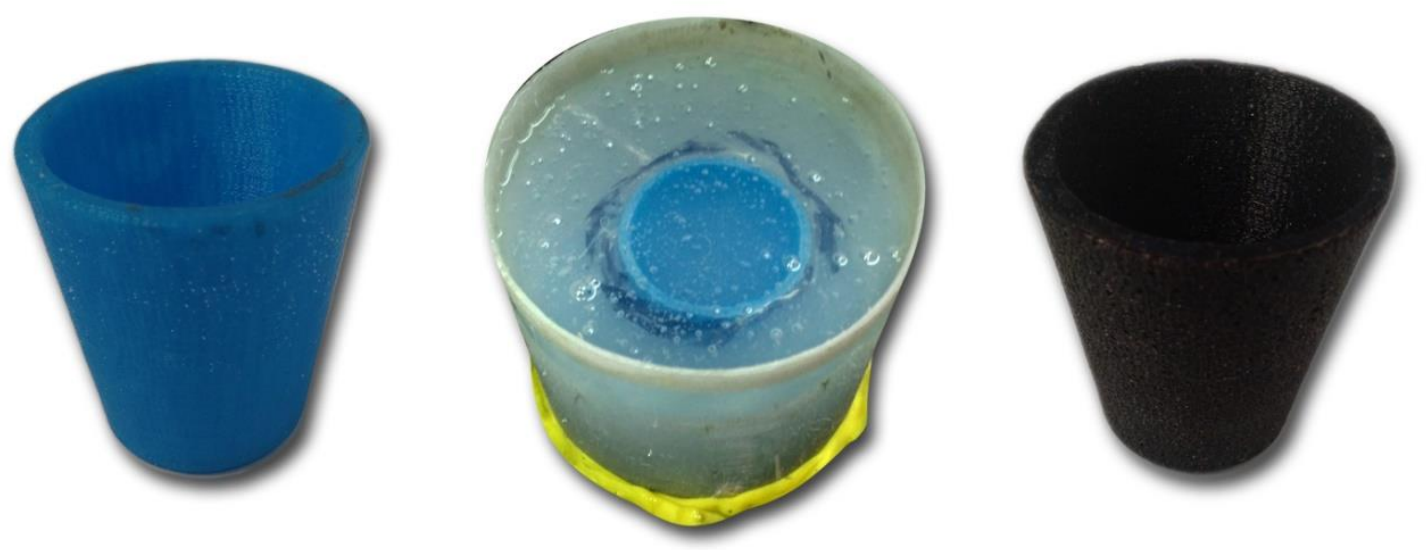

Figure 14 - 3D printed part in PLA, silicone mould and casted part.

Figure 15 presents 3 experiments carried out with this material, all with different percentages of coffee and PLA.
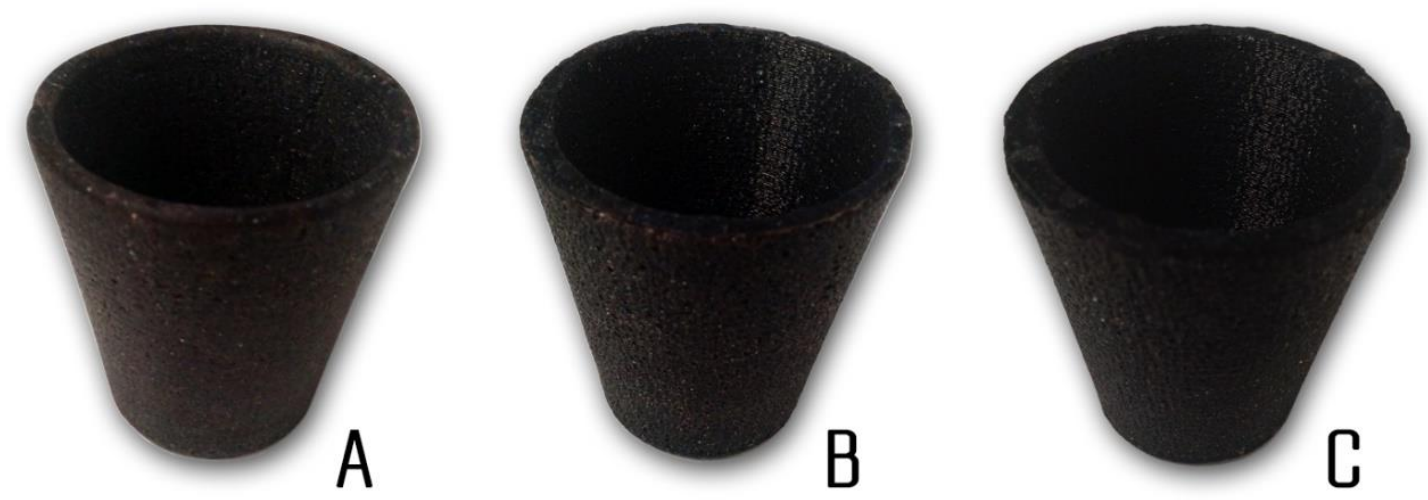

Figure 15 - Parts produced with different coffee-PLA ratios, A) $20 \%$ coffee, B) $30 \%$ coffee and C) $40 \%$ coffee. 
It is concluded, therefore, that the greater the proportion of coffee in the blend, the longer will have to be the heating of the two materials in order for them to merge. $40 \%$ is the threshold amount for this mixture. Although it is possible to increase this amount, the excess time and the thickness of the final material do not justify it.

The current state of this study can be seen in Figure 16, of experiences with hot coffee in cups casted in the silicone mould. The parts behaves according to the goal, some insulation, withstands the contact with the hot coffee and mechanical resistance, fulfilling its function perfectly.

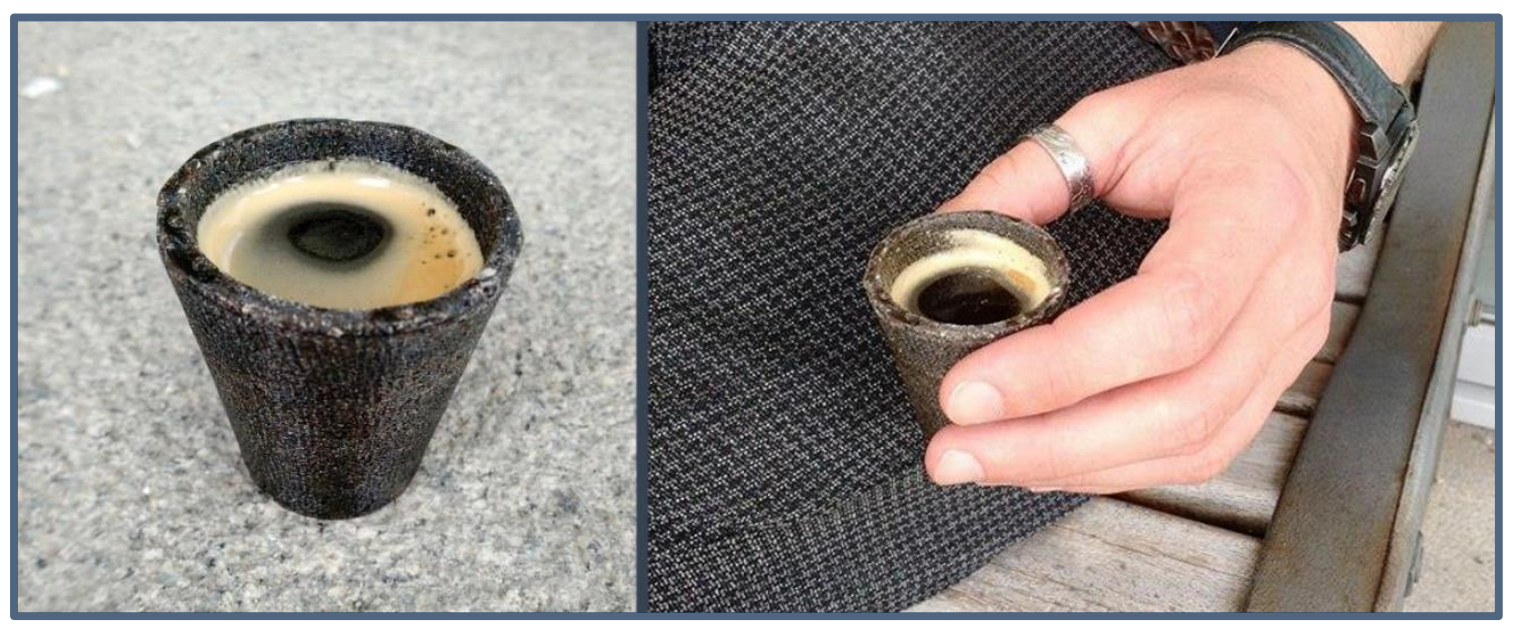

Figure 16 - Tests with hot coffee.

This mixture presents however a structural problem, since the part cannot be machine washed, due to the high temperatures to which it would be subjected. In this case, the material undergoes irreparable deformation and gets unusable. The piece has therefore to be washed by hand, preferably with cold water. 


\section{Design Proposal}

From the point of view of design, the focus was to try to create an object from the developed formulation of coffee-PLA. In an attempt to generate a semantic cycle, it seems interesting that the primary object developed based on coffee waste is a cup of coffee (Figure 17).
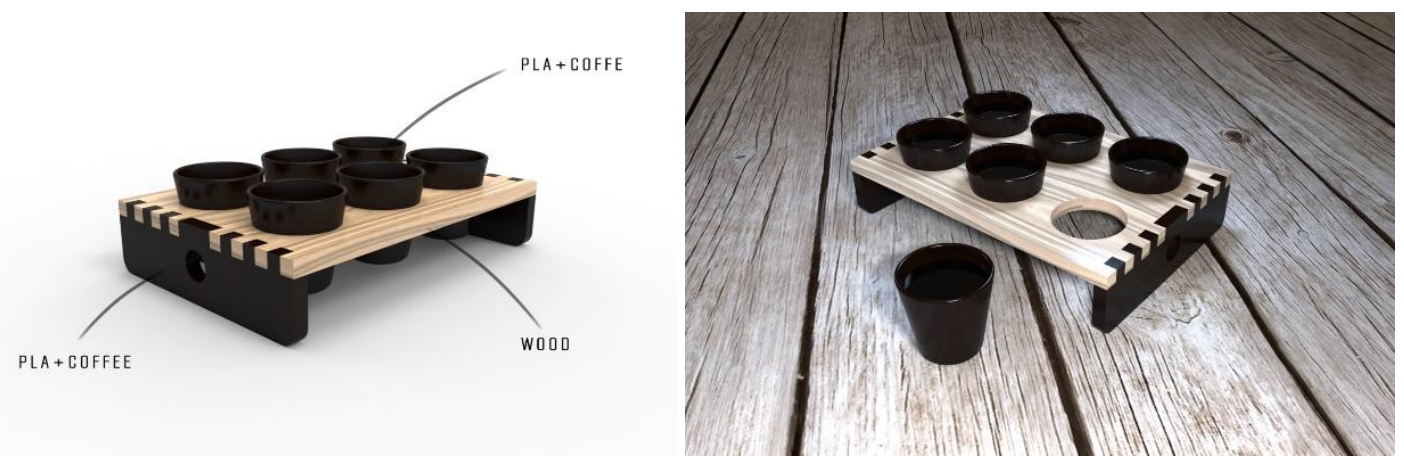

Figure 17 - Tray for coffee cups.

Taking into account the characteristics of the material created and that it is a mouldable material, the shape of the idealized objects is only limited by the imagination and of course the costs of the mould itself. Therefore, Figure 18 and Figure 19 are two examples of objects that could be crated through this technology.

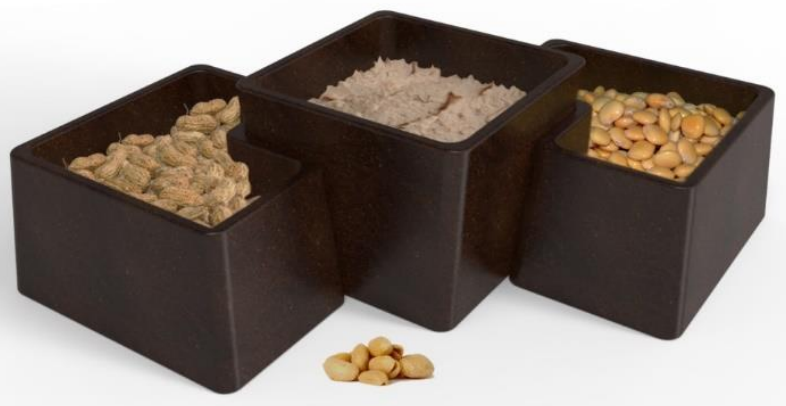

Figure 18 - Containers for appetizers. 

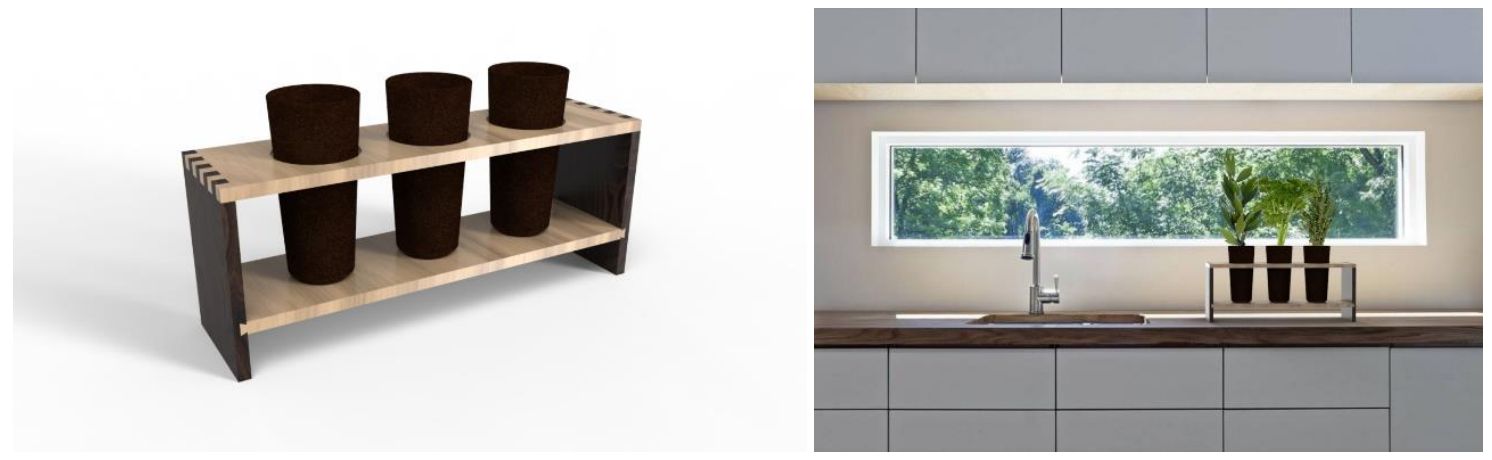

Figure 19 - Plant pots.

The use for plant pots, since it is biodegradable and there are already a number of developments in this area using coffee as a fertilizer, seems to be very interesting possibility.

\section{Conclusions}

The developed material allows the coffee waste to be reused in the universe of Industrial and Product Design. There is still some way to go to improve this technology, but at this time one can already realize that coffee does not need to be just another piece of trash, it can be turned in to a building material, very efficient and applicable to a large number of areas.

From an experimentation point of view, there have been several tests with different binding materials. It began with epoxy resin, followed by starch, in a later stage pine resin and wax, but the material that showed the best results, for the time being was PLA. Nevertheless, the material has limitations, and cannot be used at high temperatures (washing machine). It can therefore be concluded that that there is still some way to improvement to create an ideal material, but the forecasts are quite positive.

Taking into account that it is a mouldable material, the creation of objects is only limited by the imagination. 


\section{Acknowledgments}

Authors gratefully acknowledge the funding of Project NORTE-01-0145-FEDER000022 - SciTech - Science and Technology for Competitive and Sustainable Industries, cofinanced by Programa Operacional Regional do Norte (NORTE2020), through Fundo Europeu de Desenvolvimento Regional (FEDER).

\section{References}

Bhada-Tata, Daniel Hoornweg e Perinaz. 2012. "WHAT A WASTE A Global Review of Solid Waste Management". Urban Development Series knowledge Papers $\left(\mathrm{N}^{\mathrm{o}} 15\right)$.

Ceccolini, Marina. 2015. "AgriDust - Biodegradable material". Accessed 16-12-2015. https://www.behance.net/gallery/24616719/AgriDust-Biodegradable-material.

Daniel Hoornweg, Perinaz Bhada-Tata e Chris Kennedy. 2013. "Waste production must peak this century". Nature no. 502.

Eurostat. 2015. "Generation of waste by economic activity". Accessed 16-12-2015. http://ec.europa.eu/eurostat/tgm/table.do;jsessionid=ACitl4TZNMMwLpJeJFX MdIC5m7-JCB1VhQNenuSc-I-c t9uViC8!$1505779883 ?$ tab $=$ table $\&$ plugin $=1 \&$ language $=$ en $\&$ pcode $=$ ten 00106.

Gómez-de la Cruz, Francisco J., Fernando Cruz-Peragón, Pedro J. Casanova-Peláez e José M. Palomar-Carnicero. 2015. "A vital stage in the large-scale production of biofuels from spent coffee grounds: The drying kinetics". Fuel Processing Technology no. 130:188-196. http://www.sciencedirect.com/science/article/pii/S0378382014004275.

Grellier, Caroline. 2015. "The future of 3D printing in coffee grounds". Accessed 1412-2015. http://www.makery.info/en/2015/01/19/lavenir-de-limpression-3ddans-le-marc-de-cafe/.

Kaffeeform. 2015. "Kaffeeform". Acedido a 14-12-2015. http://www.kaffeeform.com/. Organization, International Coffee. 2015a. "The Current State of the Global Coffee Trade". Accessed 10-12-2015. http://www.ico.org/monthly_coffee_trade_stats.asp. 
— 2015b. "Portugal - Latest facts and figures about the global coffee trade from the International Coffee Organization". Accessed 10-12-2015. https://infogr.am//S268nTQ9nsOy58h5VJZH.

USA, 3Dom. 2015. "Woun Up". Accessed 16-12-2015.

http://www.3domusa.com/shop/wound-coffee-filled-filament/. 